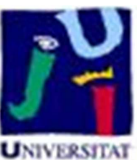

Título artículo / Títol article: A DFT Study of Structural and Electronic Properties of ZnS Polymorphs and its PressureInduced Phase Transitions

Autores / Autors

La Porta, Felipe A ; Gracia Edo, Lourdes ; Andrés Bort, Juan ; Sambrano, Julio Ricardo ; Varela, José A. ; Longo, Elson

Revista:

American Ceramic Society (2014) vol. 97, no 12

Versión / Versió:

Pre-print

Cita bibliográfica / Cita

LA PORTA, Felipe A., et al. A DFT Study of bibliogràfica (ISO 690): Structural and Electronic Properties of $\mathrm{ZnS}$ Polymorphs and its Pressure - Induced Phase Transitions. Journal of the American Ceramic Society, 2014, vol. 97, no 12, p. 4011-4018.

url Repositori UJI:

http://hdl.handle.net/10234/120444 


\title{
A DFT Study of Structural and Electronic Properties of ZnS Polymorphs and its Pressure-Induced Phase Transitions
}

\author{
F. A. La Porta, ${ }^{1,2^{*}}$ L. Gracia, ${ }^{2}$ J. Andrés, ${ }^{2}$ J. R. Sambrano, ${ }^{3}$ J. A. Varela, ${ }^{1}$ and E. \\ Longo ${ }^{1}$ \\ 'Instituto de Química, UNESP, PO Box 355, 14801-970, Araraquara, SP, Brazil. \\ ${ }^{2}$ Department of Experimental Sciences, Univ Jaumel, Castelló de la Plana, 12071, Spain \\ ${ }^{3}$ Laboratório de Smulação Molecular, UNESP, PO Box 473, 17033-360, Bauru, SP, Brazil \\ * Corresponding author: \\ felipe_laporta@yahoo.combr; Phone: +55 16 3301-9892; Fax: +55 16 3301-9691
}

A systematic first-principles investigation, by using the density functional formalis $\mathrm{m}$ with the non-local B3LYP approximation including a long-range dispersion correction, has been performed to calculate the structural and electronic properties and phase transitions under pressure of the three phases of $\mathrm{ZnS}$ (cubic zinc blende, $\mathrm{ZB}$, he xagonal wurt zite, $\mathrm{W}$, and cubic rock salt, RS). Numerical and analytical fittings have been carried out to determine the equilibrium unit cell geo metry and equation of state parameters for the $\mathrm{ZnS}$ phases. The band structures, energy gap, density of states, and vibrational frequencies and their pressure dependences are investigated. The present results illustrate that both phases, W and ZB, present very similar enthalpy and the RS phase becomes thermodynamically more stable than ZB and W structures at 15.0 and $15.5 \mathrm{GPa}$, respectively. These phase transitions are accompanied by an increase of the first shell coordination number of $\mathrm{Zn}$ atom and by a cell volu me collapse of 13.9 and $14.3 \%$ for ZB and $\mathrm{W}$ phases, respectively. The atomic contributions of the conduction and valence bands, as well the binding energy for the $\mathrm{Zn} 3 d$ orbital have been obtained.

\section{INTRODUCTION}

Zinc sulfide $(\mathrm{ZnS})$ has attracted much attention as an important semiconductor material because of its wide range of applications in photonics and its strength for novel applications, including lightemitting diodes (LEDs), electroluminescence, lasers, infrared windows, flat panel displays, sensors, catalysis, etc. $^{1-5}$

Understanding the relationship between structural and electronic properties of the semiconductor materials and their pressure-induced phase transitions is crucial to design novel nanostructures with tunable properties. ZnS presents three polymorphs: cubic zinc blende (ZB), hexagonal wurtzite (W) or 
the rarely observed cubic rock salt (RS). ${ }^{6}$ Each phase has unique physical properties, for instance, different lattice vibration properties and nonlinear optical coefficients. ${ }^{7-9}$ In particular, ZB is the thermodynamically most stable $\mathrm{ZnS}$ phase, while the $\mathrm{W}$ polymorph is stable above $1293 \mathrm{~K} .{ }^{9}$ However, RS structure can only be obtained at relatively high pressures. ${ }^{10,11} \mathrm{ZB}$ and $\mathrm{W}$ phases have industrial applications, and due their size- and shape-dependent properties both materials are capable of being obtained in different ways in order to tune their properties to specific needs. ${ }^{9,12,13}$ In this context, with decreasing the particle size, the relative stability of the two phases changes and a low temperature synthesis of ZnS nanoparticles with W structure has been reported. ${ }^{6,13-15}$

Several routes are described in the literature to obtain $\mathrm{ZnS}$ with different morphologies ${ }^{6,16-23}$ and a considerable effort has been devoted to characterized theses materials by means of different techniques such as such x-ray diffraction (XRD), ${ }^{17,18}$ extended X-ray absorption fine structure, ${ }^{19}$ high-resolution transmission electron microscopy (HRTEM), ${ }^{20}$ Fourier transform infrared (FT-IR) and Raman spectroscopy, $^{8-21}$ X-ray photoelectron spectroscopy $(\mathrm{XPS})^{6}$ and photoluminescence (PL) measurements. ${ }^{6,22,23}$

Theoretical and computational studies, based on the Density Functional Theory (DFT) ${ }^{24,25}$ have emerged to provide important information regarding the electronic and structural properties of solid materials and molecules, ${ }^{24-29}$ and have shown great value, not only in the in interpretation of experiments, but also in the prediction of important aspects of new properties and in the design of new devices. Nevertheless, despite the recent improvements in DFT, there are still difficulties in using DFT to properly describe van der Waals interactions (dispersion) and charge transfer excitations due to the lack of exact Hartree-Fock exchange in some functionals. ${ }^{30-34}$ To overcome these limitations, an empirical correction to include dispersion interactions in DFT methods has been proposed by Grimme. ${ }^{35-}$ ${ }^{37}$ It is a damped pairwise London-type term of the form $\mathrm{C}_{6} \mathrm{R}^{-6}$ and this correction is applied to calculate 
more accuracy values of energies and gradients in the simulation of periodic models, and it is implemented in CRYSTAL 09 code. ${ }^{38}$

Among the most interesting phenomena, the pressure-induced $\mathrm{ZnS}$ polymorphism $(\mathrm{ZB}, \mathrm{W}$ and RS) is specially relevant and has been a subject of many theoretical and experimental studies to understand the observed changes under pressure. ${ }^{11,17,39-41}$ However, understanding this polymorphism at atomic level is very important for technological applications of materials based on $\mathrm{ZnS}$ and computational simulations can shed some light on to this important issue. Knowledge of the pressuredependent phase stability and the relationship between physical/chemical properties and crystal/electronic structures can offer the way to systematically search new complex metal oxides. In this sense, this work can be considered as a prolongation of previous high pressure studies of pressure induced structural phase transitions of different binary and ternary metal oxides. ${ }^{42,43}$

In this work, we report periodic first-principle calculations based on DFT to obtain the energy, geometry, and vibrational frequency by including the empirical dispersion correction on $\mathrm{ZnS}$ polymorphs and its pressure-induced phase transitions. The paper is organized as follows. Section 2 describes the computational details. In section 3, we present our theoretical results together with the discussion concerning the local compressibility and phase stability, as well as the electronic structure analysis for the different phases; in addition, vibrational properties as derived from calculations are discussed in detail. Finally, we summarize our main conclusions in Section 4.

\section{COMPUTATIONAL METHODS}

In the present study, we use periodic DFT calculations with the B3LYP-D hybrid functional ${ }^{44,45}$ with a long-range dispersion correction, as implemented in the CRYSTAL09 computer code. ${ }^{38}$ CRYSTAL 09 uses Gaussian-type basis set to represent crystalline orbitals as a linear combination of Bloch functions defined in terms of local functions (atomic orbitals). ${ }^{46}$ A long-range dispersion correction proposed by 
Grimme has been considered in the calculations. ${ }^{35-37}$ The zinc and sulfur atomic centers were described by all-electron $6-31 \mathrm{G}^{*}$ and $86-311 \mathrm{G}^{*}$ basis sets, respectively. Basis sets were optimized in this study and are available in supplementary material. Optimization of the exponents for the outermost $s p$ and $d$ shells was carried out to minimize the total energy of the structure at experimental parameters $\left(\alpha_{\mathrm{sp}(\mathrm{Zn})}=0.14349998, \alpha_{\mathrm{d}(\mathrm{Zn})}=0.73000001\right.$ and $\left.\alpha_{\mathrm{sp}(\mathrm{S})}=0.38000002\right){ }^{22}$ The Powel algorithm method ${ }^{47}$ was used to perform the optimization procedure of the basis sets. The level of calculation accuracy for the Coulomb and exchange series was controlled by five thresholds set to $\left(10^{-8}, 10^{-8}, 10^{-8}, 10^{-8}\right.$, and $10^{-}$ ${ }^{18}$ ). The shrinking (Monkhorst-Pack) ${ }^{48}$ factor was set to 6 , which corresponds to 80 independent $k$-points in the irreducible part of the Brillouin zone integration.

Conventional unit cells of the three polymorphs belong to the $F-43 m(\mathrm{ZB}), P 6_{3} m c(\mathrm{~W})$ and $F m$ 3m(RS) spaces groups (see Figure 1). Lattice parameters, for ZB and RS structures, and also atomic positions for the W structure were fully optimized. The lattice parameters and atomic positions obtained by means by optimized structure in zero pressure equilibrium properties for ZnS polymorphs were used in the Diamond Crystal and Molecular Structure Visualization program (Version 3.2f for Windows) ${ }^{49}$ to carry out the XRD simulation. To take into account the effect of pressure on this system, all the geometric parameters $(a, c$ and $u)$ were optimized for $\mathrm{ZnS}$ polymorphs. Fittings with a Birch-Murnaghan third-order equation of state (EOS) of the computed energy-volume data provide values of the zero-pressure bulk modulus $\left(B_{0}\right)$ and its pressure derivative $\left(B_{0}^{\prime}\right)$ as well as enthalpy-pressure curves for the polymorphs studied..$^{50}$

The characteristics and properties of $\mathrm{ZnS}$ polymorphs (ZB, W and RS) was evaluated and discussed in terms of charges and deformations induced by pressure on the $\mathrm{ZnS}$ clusters. The Xcrys Den program ${ }^{51}$ was used for the band structure drawing design. The analysis of the vibrational modes and their corresponding frequencies were calculated through numerical second derivatives of the total energies as implemented in the CRYSTAL09 package. 


\section{RESULTS AND DISCUSSION}

The structure of the three phases of $\mathrm{ZnS}$ and their respective XRD simulation are shown in Figure 1. These results are in very good agreement with other studies ${ }^{5,6,22,52-55}$ The theoretical lattice parameters and other theoretical and experimental data are displayed in Table 1. In W and ZB structures each Zn atom is surrounded by four $\mathrm{S}$ atoms forming tetrahedral clusters $\left[\mathrm{ZnS}_{4}\right]$ which share one or two corners, respectively. $\mathrm{W}$ phase is more compact than $\mathrm{ZB}$ phase, and the $\mathrm{W}$ phase shows a lack of a center of symmetry which generates a residual polarization in this $\left[\mathrm{ZnS}_{4}\right]$ cluster. The optimized $\mathrm{W}$ structure belongs to the hexagonal space group $P 6_{3} m c$ with the lattice parameters: $a=3.79$ and $\mathrm{c}=6.14 \AA$ and contains two formula units of $\mathrm{ZnS}$ per unit cell. The ratio of $\mathrm{c} / \mathrm{a}=1.621$ deviates slightly from the value of $\mathrm{c} / \mathrm{a}=\sqrt{ } 8 / 3=1.633$ for the hexagonal phase of $\mathrm{ZnS} .{ }^{56}$ For RS phase in the $\mathrm{ZnS}$ crystal, each $\mathrm{Zn}$ atom is surrounded by six S atoms at the corners of the $\left[\mathrm{ZnS}_{6}\right]$ octahedral clusters. The structural characteristics of these clusters, as building blocks of this system, may explain some particular properties of $\mathrm{ZnS}$ crystal.

Table 1: Comparative results between the structural parameters and unit cell volume of $\mathrm{ZnS}$ polymorphs in the equilibrium configuration obtained in this work with those published in the literature.

\begin{tabular}{ccccc}
\hline Polymorphs & $\mathrm{a}(\AA)$ & $\mathrm{c}(\AA)$ & $\mathrm{u}$ & Ref. \\
\hline ZB & 5.42 & - & 0.250 & This work \\
& 5.33 & - & - & 39 \\
& 5.58 & - & - & 41 \\
& 5.42 & - & - & 53 \\
\hline $\mathrm{W}$ & 3.79 & 6.14 & 0.379 & This work \\
& 3.82 & 6.26 & - & 4 \\
& 3.82 & 6.26 & 0.375 & 52 \\
$\mathrm{RS}$ & 3.83 & 6.26 & 0.379 & 22 \\
& 5.09 & - & 0.500 & This work \\
& 5.01 & - & - & 39 \\
& 5.21 & - & - & 41 \\
& 5.02 & - & - & 54 \\
\hline
\end{tabular}



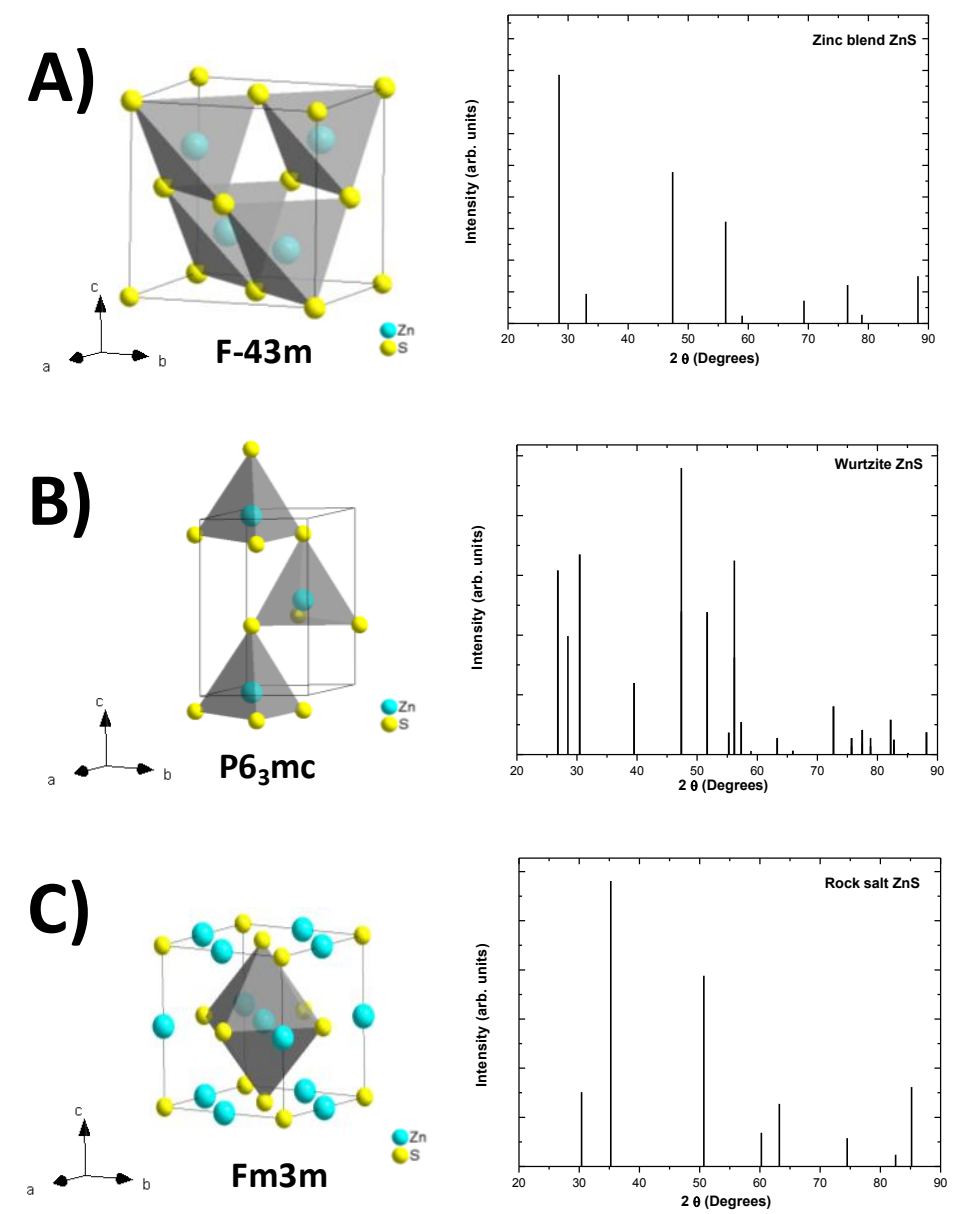

Figure 1: Schematic representation of the unit cells (left) and simulated XRD patterns (right) for the ZnS phases: a) Zinc blende, b) Wurtzite and c) Rock salt.

Raman spectroscopy is a well known and useful method for investigating the behavior of symmetry changes in semiconductor materials. ${ }^{21,57-60}$ The theoretical Raman-active modes are shown in the Table 2. ZB structure is a polar crystal without an inversion center, and it belongs to the point group F-43m with only four particles per unit cell and has three optical modes triply degenerate with symmetry $\left(\Gamma_{15}(\mathrm{~F})\right)$ and both of which are infrared and Raman active. ${ }^{21,59}$ In particular, the experimental Raman spectrum for ZB structure has been reported by Nilsen, ${ }^{59}$ and according to these results, two bands appear that are assigned the transverse optic (TO) mode at $271 \mathrm{~cm}^{-1}$ and the longitudinal optic (LO) mode with a higher frequency at $352 \mathrm{~cm}^{-1}$. The symmetry of these modes and the predicted frequencies 
for $\mathrm{ZnS}$ polymorphs is well established by their polarization characteristics..$^{8,21,59}$ The $\mathrm{W}$ structure belongs to the point group $P 6_{3} m c$, with only two particle per unit cell and has six optical modes $\left(\Gamma=\mathrm{A}_{1}\right.$ $\left.+2 B_{1}+E_{1}+2 E_{2}\right)$, being the $A_{1}, E_{1}$ and $E_{2}$ Raman active and $A_{1}$ and $E_{1}$ modes infrared active. ${ }^{8,21,59} B_{1}$ modes are silent modes in both types of spectra. ${ }^{8}$

Table 2: Comparative results between the experimental and theoretical Raman modes of $\mathrm{ZnS}$ polymorphs in $\mathrm{cm}^{-1}$.

\begin{tabular}{cccc}
\hline ZB structure & This work & Ref. 21 & Ref. 58 \\
\hline F & 328.01 & $277(\mathrm{TO})$ & $271(\mathrm{TO})$ \\
& & $340(\mathrm{LO})$ & $352(\mathrm{LO})$ \\
\hline W structure & This work & Ref. 21 & Ref. 8 \\
\hline $\mathrm{E}_{2}$ & 81.70 & 76 & 72 \\
$\mathrm{~A}$ & 315.06 & 287 & 273 \\
$\mathrm{E}_{1}$ & 328.34 & 288 & 273 \\
$\mathrm{E}_{2}$ & 333.08 & 296 & 286 \\
\hline
\end{tabular}

The band structure and DOS of these materials were calculated and the results are shown in Figure 2. An analysis of the band structure (see Figure 2 (a-c)), shows that both ZB and W phase have a direct band gap at the $\Gamma$ point, while RS phase has an indirect band gap at the $\mathrm{L} \rightarrow \mathrm{X}$ point. The calculated band gaps for $\mathrm{ZnS}$ polymorphs are 4.10, 4.14 and $1.45 \mathrm{eV}$ for $\mathrm{ZB}, \mathrm{W}$ and $\mathrm{RS}$ respectively, in good accordance with the values reported in the literature. ${ }^{6,22,39}$ Theoretical calculations for the $\mathrm{W}$ phase were reported previously, $^{22}$ not including long-range corrections using the same theoretical level. The reported theoretical value of the band gap for the $\mathrm{W}$ phase was $3.88 \mathrm{eV}$ while in present study, there is an increase in the estimated value for the band gap of $4.14 \mathrm{eV}$. These results show that the inclusion of dispersion in the DFT calculation generates an increase of approximately $6.3 \%$ in band gap value for the phase W. Similar trends were observed for other phases. 
An analysis of the DOS for the bulk $\mathrm{ZnS}$ polymorphs shows that uppermost valence band (VB) consists mainly of S $3 p$ orbitals with a lesser contribution of hybrids $\mathrm{Zn} 4 s$ and $4 p$ orbital states. The presence of $\mathrm{Zn} 3 d$ states in the $\mathrm{VB}$ in the $\mathrm{ZnS}$ polymorphs models reveals a strong bonding character between $\mathrm{S}$ and $\mathrm{Zn}$. The conduction band (CB) consists mainly of hybridization of $\mathrm{Zn} 4 s$ and $4 p$ orbital states with a small contribution of $\mathrm{S} 3 p$ orbitals. This results is also found in the DOS analysis of $\mathrm{Zn}-$ based II-VI semiconductor materials. ${ }^{61}$ In addition, we have calculated the binding energies (BEs), as the difference $\Delta \mathrm{E}=\mathrm{E}^{\mathrm{HOMO}}-\mathrm{E}^{\text {core-level }}$, of the $\mathrm{Zn} 3 d$ orbitals for the three $\mathrm{ZnS}$ polymorphs, and the results are as follow: $\mathrm{ZB}, \mathrm{W}$ and $\mathrm{RS}$ structures of $7.43,6.98$ and $7.67 \mathrm{eV}$, respectively.

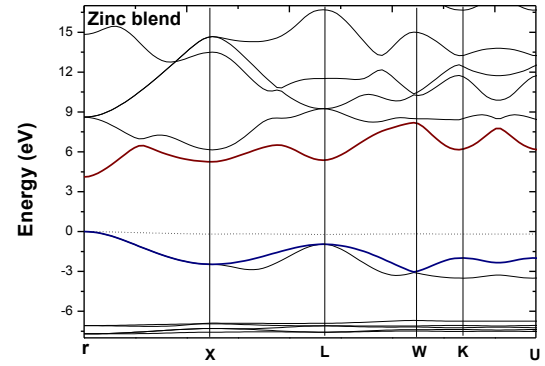

(a)

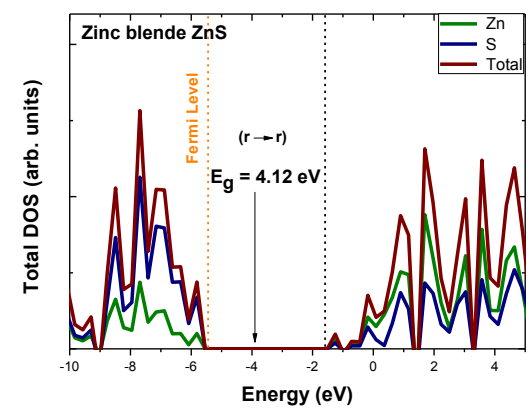

(d)

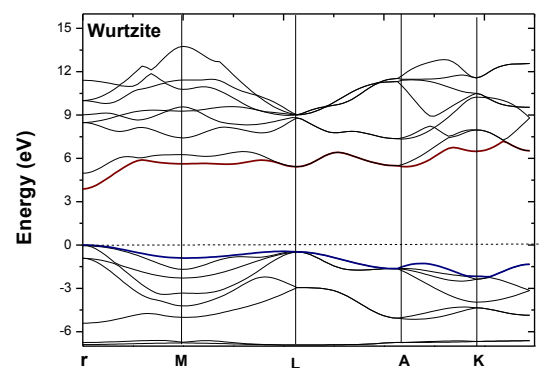

(b)

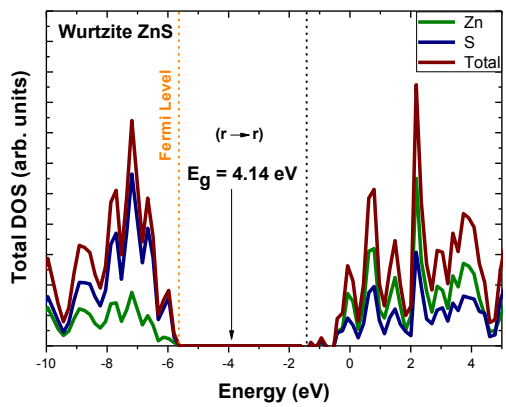

(e)

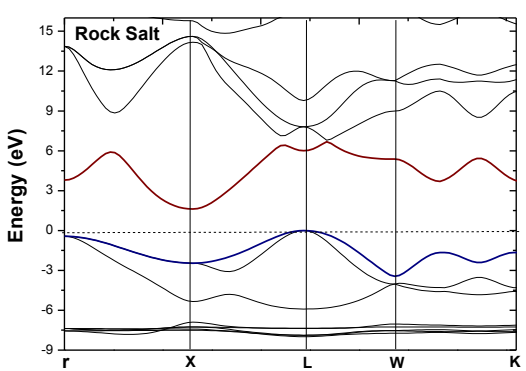

(c)

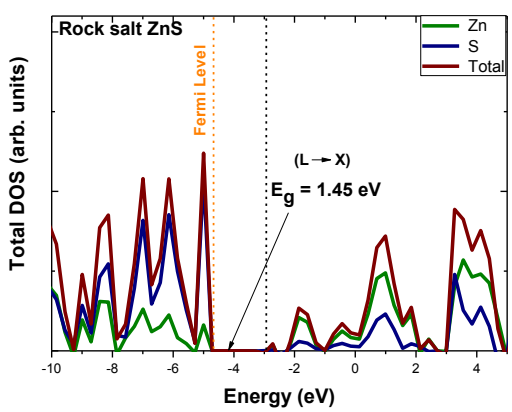

(f)

Figure 2: Band structures and Projected DOS on atomic levels for ZnS polymorphs: (a-d) Zinc blende, (b-e) Wurtzite and (c-f) Rock salt. 
The atomic contributions of the VB and $\mathrm{CB}$ in DOS analysis, named as atoms present at the active site (APAS), have been obtained following a recently developed protocol; for more details on this methodology see reference, ${ }^{62,63}$ and the results for $\mathrm{ZnS}$ polymorphs are presented in Table 3 . Our results can reveal the fundamental relationship between the nature of chemical bonding and bulk properties in $\mathrm{ZnS}$ polymorphs, showing the presence of mixed ionic-covalent bonding for these materials. The bonding is predominantly covalent for $\mathrm{ZB}$ and $\mathrm{W}$ phase s while it is more ionic for RS structure. The $\mathrm{Zn}-\mathrm{S}$ distance is $2.308 \AA, 2.313 / 2.316 \AA$ and $2.510 \AA$ for $\mathrm{ZB}, \mathrm{W}$ and $\mathrm{RS}$, respectively. Figure 3, the charge density contours are depicted for bulk $\mathrm{ZnS}$ polymorphs. A detailed analysis of these results point out that a larger contribution of covalent bond in the $\mathrm{ZnS}$ clusters causes an energetic stabilization of the crystal structure. These results are in good agreement with previous studies reported by Jaffe et al. ${ }^{41}$

Table 3: APAS contribution (\%) for the density of states in $\mathrm{ZnS}$ polymorphs.

\begin{tabular}{cccc}
\hline \multirow{2}{*}{ Polymorphs } & atoms & \multicolumn{2}{c}{ APAS contribution \% } \\
\cline { 3 - 4 } & & VB & CB \\
\hline ZB & Zn & 30.16 & 63.05 \\
& $\mathrm{~S}$ & 69.84 & 36.95 \\
\hline $\mathrm{W}$ & $\mathrm{Zn}$ & 29.90 & 61.65 \\
& $\mathrm{~S}$ & 70.10 & 38.35 \\
\hline $\mathrm{RS}$ & $\mathrm{Zn}$ & 31.90 & 71.58 \\
& $\mathrm{~S}$ & 68.10 & 28.42 \\
\hline
\end{tabular}



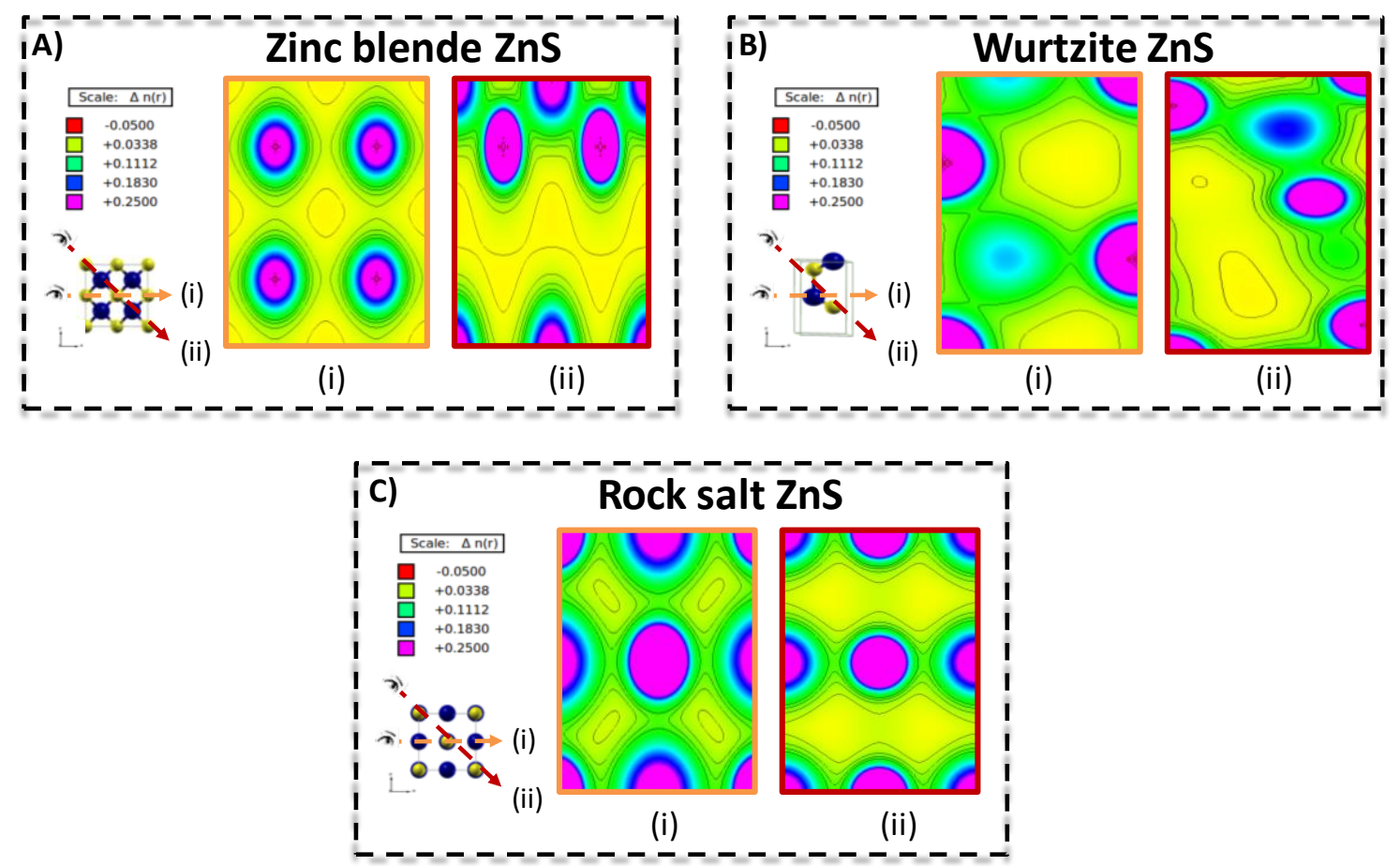

Figure 3: Charge density maps in ZnS polymorphs: a) Zinc blende, b) Wurtzite and c) Rock salt.

Calculated lattice parameters and distances between the $\mathrm{Zn}$ and $\mathrm{S}$ atoms at different pressures as well as the bulk modulus and its pressure derivative for the three phases of $\mathrm{ZnS}$ structure are listed in Table 4 . For the ZB phase we have obtained the EOS being $\mathrm{B}_{0}=115.6 \mathrm{GPa}$ and $\mathrm{B}_{0}{ }^{\prime}=3.3$, higher than the experimental value reported by Nazzal et al. ${ }^{54}$ of $83.3 \mathrm{GPa}$. For the $\mathrm{W}$ phase, the bulk modulus was $\mathrm{B}_{0}$ $=112.3 \mathrm{GPa}$ and $\mathrm{B}_{0}{ }^{\prime}=3.5$, a larger value than other experimenta $\mathrm{l}^{64}$ and theoretical studies. ${ }^{39}$ Regarding the polyhedral changes taking place as the pressure is applied, calculations show that the distortion of the $\left[\mathrm{ZnS}_{4}\right]$ tetrahedral clusters is reduced in the $\mathrm{W}$ phase, and at $35 \mathrm{GPa}$ there is only one distance $\mathrm{Zn}-\mathrm{S}$.

Figure 4(a) shows the energy versus volume curves for the three different structures of $\mathrm{ZnS}$. The enthalpy curves are plotted as a function of pressure in Figure 4(b). Both phases, W and ZB present very similar enthalpy. Upon further compression we found that rock-salt structure become thermodynamically more stable than $\mathrm{ZB}$ and $\mathrm{W}$ at 15 and $15.5 \mathrm{GPa}$, respectively. These transition pressures are in excellent agreement with the experimental values of $15.0-16.0 \mathrm{GPa}{ }^{65,66}$ 


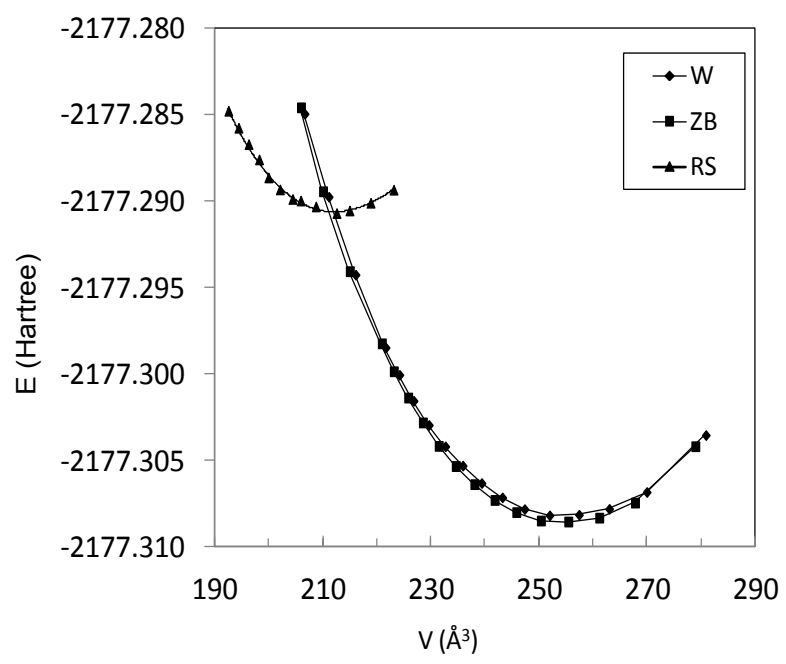

(a)

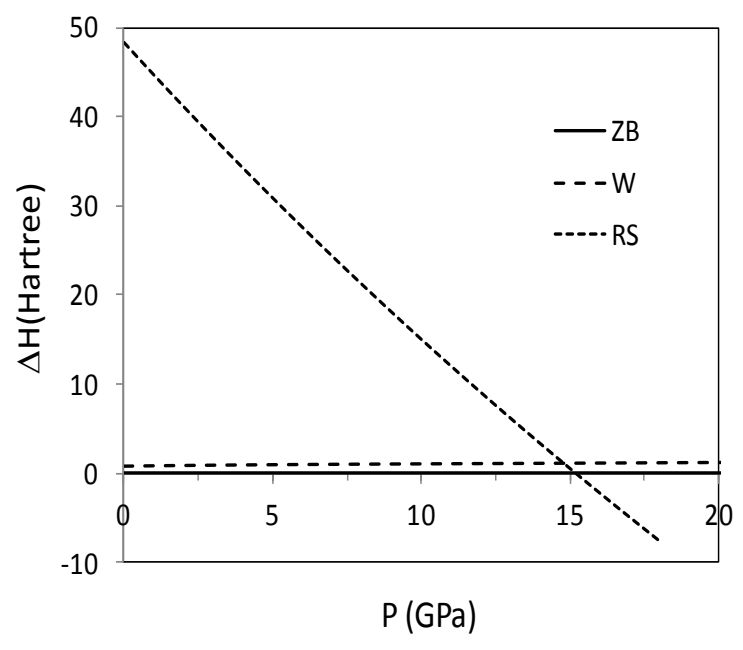

(b)

Figure 4: (a) Energy versus volume curves for the three different structures of ZnS. (b) The enthalpy curves as a function of pressure.

The transition to RS involves a larger volume collapse. For the RS phase the $\mathrm{B}_{0}=155.4 \mathrm{GPa}$ and $\mathrm{B}_{0}{ }^{\prime}=5.1$, higher than the experimental value reported by Nazzal et al. ${ }^{54}$ of $104.4 \mathrm{GPa}$, a bulk modulus approximately $25 \%$ larger than the value for $\mathrm{ZB}$ and $\mathrm{W}$ structures. This decrease of the bulk compressibility is caused by the rearrangement of the polyhedral units that takes place at the transition.

The W-to-RS phase transition is a reconstructive phase transition and the transformation mechanism is associated with large atomic displacements and strain. The volume reduction during the phase transition for both $\mathrm{ZB}$ and $\mathrm{W}$ phases is predicted to be about 13.9 and $14.3 \%$, respectively, which are comparable with the experimental result of $15.7-17 \%,{ }^{64}$ and the theoretical result of $14.4 \% .{ }^{67}$ Despite the controversy about the value of transition pressure obtained by experiments and theory, both clearly demonstrate that the transition pressures of the W-to-RS and ZB-to-RS phase changes are very close to each other. From enthalpy calculations, we can state that no phase transition between the bulk ZB and W phases occurs with the application of pressure alone because their enthalpies are always parallel to each 
other. However, this is not the case for $\mathrm{W}$ nanocrsytals as clearly demonstrated in experiment. ${ }^{17,68}$ This $^{\text {Th }}$ behavior of nanocrystals is probably associated with the presence of significant surface energy effects.

The average $\mathrm{Zn}-\mathrm{S}$ bond distances increased in $8.8 \%$ and $9.0 \%$ at the transition pressure $\mathrm{W}$-to-RS and ZB-to-RS of 15.0 and $15.5 \mathrm{GPa}$, respectively. Table 4 shows the pressure evolution of the unit-cell parameters of $\mathrm{ZnS}$ phases. An analysis of Table 4 shows that the variation with pressure of the $c$ parameter is higher than for the a parameter for the $\mathrm{W}$ structure. However, the computed linear compressibilities of $1.3 \times 10^{-3} \mathrm{GPa}^{-1}$ and $1.7 \times 10^{-3} \mathrm{GPa}^{-1}$ for $\kappa_{\mathrm{c}}$ and $\kappa_{\mathrm{a}}$, respectively, show a slightly anisotropic behaviour for $\mathrm{W}$ structure. From these numbers we recover $\mathrm{B}_{0}$ values consistent with those deduced from $p-V$ data. Therefore, $\mathrm{W}$ structure is not significantly compressed along c-direction, according to previous work of Durandurdu et al., ${ }^{39}$ in which it is reported a W-to-RS mechanism different from other hexagonal and tetragonal paths observed in a variety of materials with W structure. The ZB-to-RS transformation mechanism of $\mathrm{ZnS}$ is well established in the literature ${ }^{57,69-71}$ by means of an orthorrombic pathway (via an intermediate state with Pmm2 symmetry). In particular, the shape of the cluster is determined by the contribution of covalent binding, preferring the tetrahedral coordination in the $\mathrm{ZnS}$ clusters for $\mathrm{ZB}$ and $\mathrm{W}$ structures. On the other hand, with increasing of the $\mathrm{Zn}-\mathrm{S}$ bond ionic character, as is evidenced for RS structure, an octahedral coordination of the ZnS clusters is favored. 
Table 4: Calculated lattice parameters from primitive unit cells and distances between the $\mathrm{Zn}$ and $\mathrm{S}$ atoms at different pressures as well as the bulk modulus and its pressure derivative for the three phases of $\mathrm{ZnS}$ structure.

\begin{tabular}{cccc}
\hline \multicolumn{4}{c}{ Zinc Blende $\left(\mathrm{B}_{0}=115.6 \mathrm{GPa}\right.$ and $\left.\mathrm{B}_{0}{ }^{\prime}=3.3\right)$} \\
\hline $\mathrm{P}(\mathrm{GPa})$ & $\mathrm{a}(\AA)$ & $\mathrm{V}\left(\AA^{3}\right)$ & $\mathrm{Zn}-\mathrm{S}(\AA)$ \\
\hline 0.0 & 3.77 & 37.84 & 2.308 \\
4.0 & 3.72 & 36.42 & 2.278 \\
8.0 & 3.68 & 35.27 & 2.254 \\
12.0 & 3.65 & 34.29 & 2.233 \\
16.0 & 3.62 & 33.45 & 2.215 \\
20.0 & 3.59 & 32.73 & 2.199 \\
25.0 & 3.56 & 31.85 & 2.179 \\
30.0 & 3.53 & 31.12 & 2.162 \\
35.0 & 3.51 & 30.51 & 2.148
\end{tabular}

\begin{tabular}{|c|c|c|c|c|}
\hline \multicolumn{5}{|c|}{ Wurtzite $\left(\mathrm{B}_{0}=112.3 \mathrm{GPa}\right.$ and $\left.\mathrm{B}_{0}^{\prime}=3.5\right)$} \\
\hline$\overline{\mathrm{P}(\mathrm{GPa})}$ & $\mathrm{a}(\AA)$ & $\mathrm{c}(\AA)$ & $\mathrm{V}\left(\AA^{3}\right)$ & $\mathrm{Zn}-\mathrm{S}(\AA)$ \\
\hline 0.0 & 3.79 & 6.14 & 38.14 & $2.312 / 2.316$ \\
\hline 4.0 & 3.74 & 6.06 & 36.64 & $2.282 / 2.286$ \\
\hline 8.0 & 3.70 & 6.00 & 35.47 & $2.258 / 2.261$ \\
\hline 12.0 & 3.66 & 5.95 & 34.47 & $2.236 / 2.239$ \\
\hline 16.0 & 3.63 & 5.90 & 33.60 & $2.218 / 2.219$ \\
\hline 20.0 & 3.60 & 5.86 & 32.83 & $2.201 / 2.202$ \\
\hline 25.0 & 3.57 & 5.81 & 32.01 & $2.182 / 2.183$ \\
\hline 30.0 & 3.54 & 5.77 & 31.27 & $2.165 / 2.166$ \\
\hline 35.0 & 3.51 & 5.74 & 30.61 & $2.150 / 2.150$ \\
\hline \multicolumn{5}{|c|}{ Rock salt $\left(\mathrm{B}_{0}=155.4 \mathrm{GPa}\right.$ and $\left.\mathrm{B}_{0}{ }^{\prime}=5.1\right)$} \\
\hline $\mathrm{P}(\mathrm{GPa})$ & & & $\mathrm{V}\left(\AA^{3}\right)$ & Zn-S $(\AA)$ \\
\hline 0.0 & & & 31.48 & 2.510 \\
\hline 4.0 & & & 30.50 & 2.480 \\
\hline 8.0 & & & 29.93 & 2.464 \\
\hline 12.0 & & & 29.36 & 2.449 \\
\hline 16.0 & & & 28.80 & 2.433 \\
\hline 18.0 & & & 28.52 & 2.425 \\
\hline
\end{tabular}

Lattice vibrations play an important role for materials modeling, and their behavior under pressure provides useful information regarding structural instabilities and phase transformations. The frequencies $(\omega)$ of Raman-active modes for the $\mathrm{W}$ structure have been calculated as well as the Grüneisen 
parameters $\left(\gamma=B_{0} \partial \ln \omega / \partial P\right)$ from their pressure dependences. Figure 5 shows the shift of the corresponding frequencies for the Raman active modes of W structure as a function of pressure. Table 5 lists for $\mathrm{W}$ and $\mathrm{ZB}$ structures the calculated pressure-coefficients of all modes and their Grüneisen parameters calculated using the value of $B_{0}=112.3 \mathrm{GPa}$ found in the present study. It can be seen that the $\mathrm{W}$ structure presents one soft mode characterized by a decrease of the vibrational frequency with pressure. This mode has $E_{2}$ symmetry and is associated to an asymmetric bending between $\mathrm{Zn}-\mathrm{S}$ units, suggesting that at higher pressure the hexagonal phase should undergo a transition involving a strong coupling between a zone-centre optic mode and a strain, in this case of $E_{2}$ symmetry. The pressure dependence of Raman modes as well as Grüneisen parameters are according to referenced optical phonons in $\mathrm{ZnO}^{72}$

Figure 5. Pressure dependence of the first-order Raman modes for W structure.

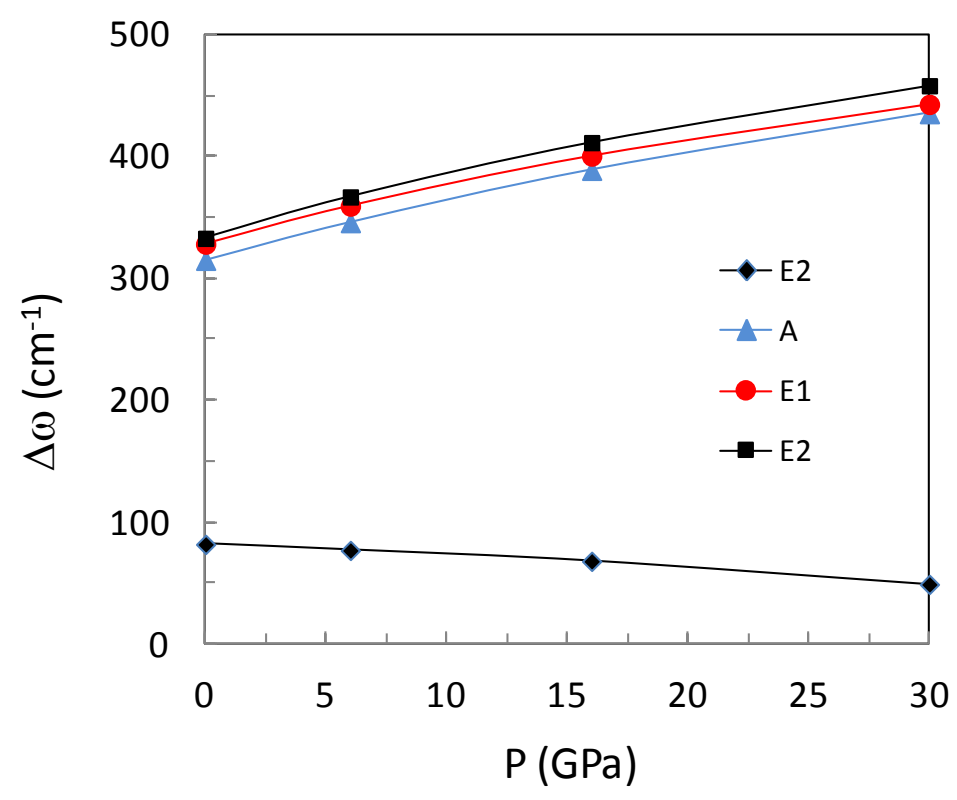


Table 5. Calculated pressure-coefficients of Raman modes of Wurtzite and Zinc Blende, and their Grüneisen parameters.

\begin{tabular}{llccc}
\hline & & $\omega_{0}$ & $\delta \omega / \delta \mathrm{P}$ & $\gamma_{0}$ \\
\hline \multirow{4}{*}{ Wurtzite } & $\mathrm{E}_{2}$ & 81.70 & -0.89 & -1.23 \\
& $\mathrm{~A}$ & 315.06 & 4.30 & 1.53 \\
& $\mathrm{E}_{1}$ & 328.34 & 4.11 & 1.41 \\
& $\mathrm{E}_{2}$ & 333.08 & 4.46 & 1.50 \\
\hline Zinc Blende & $\mathrm{F}$ & 358.6 & 4.01 & 1.29 \\
\hline
\end{tabular}

The pressure dependence of the band gap of $\mathrm{ZnS}$ structures is shown in the Figure 6. In particular, the band gap depends of the degree of structural and electronic disorder in the lattice. The DOS analysis of $\mathrm{ZnS}$ polymorphs evidence changes in the $\mathrm{VB}$ and $\mathrm{CB}$, increasing the value of the band gap with pressure. There is a major shift in the $\mathrm{CB}$ of $\mathrm{ZnS}$ polymorphs (see Figure 6) and it is possible to monitor the band gap behavior with the increasing pressure. These structural transformations induced by pressure causes a change in the electronic structure of the ZnS polymorphs (see Figure 6). Similar findings has been reported for other systems. ${ }^{42,43}$

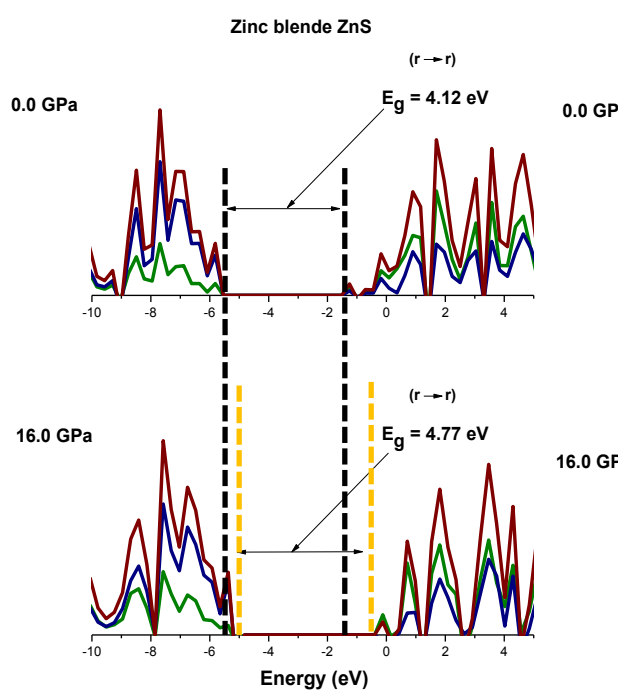

(a)

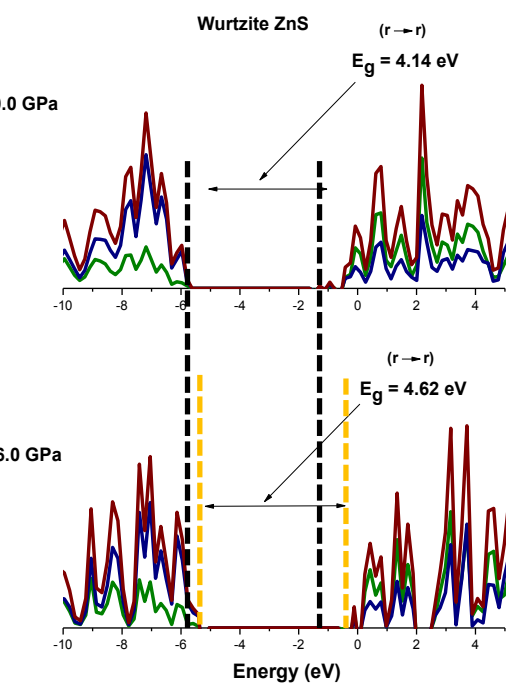

(b)

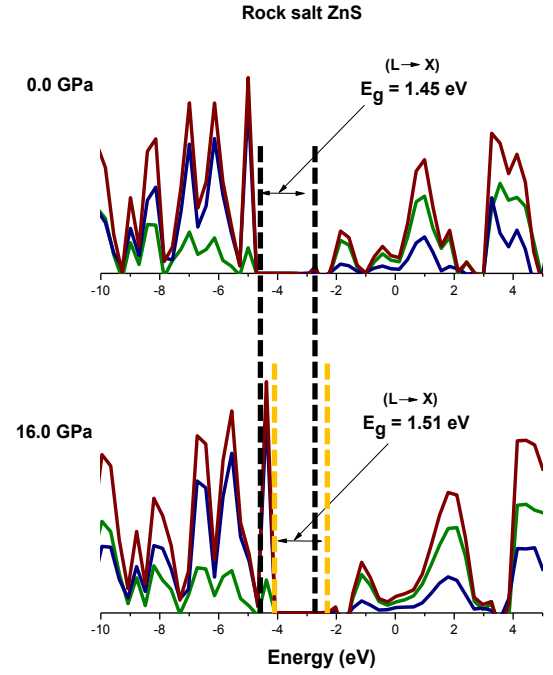

(c)

Figure 6: Projected density of states (PDOS) of ZnS polymorphs with the pressure. 
According to our calculations a linear behavior is observed between the values of the band gap with increasing pressure. Our results show greater variation in the value of the band gap energies with increasing pressure to the $\mathrm{ZB}$ and $\mathrm{W}$ phases, while a small change is observed for RS phase. These

results follow the same trend of the theoretical study of Gupta et al. ${ }^{73}$ and Huang et al. ${ }^{74}$ but with a better description in value of the band gap of these materials and in very good agreement with the experimental results reported by Ves et al. ${ }^{67}$

\section{CONCLUSIONS}

We have investigated the structural and electronic properties and its pressure-induced phase transitions of ZnS polymorphs by periodic DFT calculations with a long-range dispersion correction. Our results confirm that this method provides a good description of the effect of the phase transition pressure in these materials.

The main results of the present work can be summarized as follows: i) Enthalpy curves as a function of pressure show that both phases, $\mathrm{W}$ and $\mathrm{ZB}$, present very similar entalphy, and transition pressures of the W-to-RS and ZB-to-RS are very close to each other, at $15 \mathrm{GPa}$ and $15.5 \mathrm{GPa}$, respectively. These phase transitions are accompained by an increase of the first shell coordination number of $\mathrm{Zn}$ atom and the unit cell volume collapse of 13.9 and $14.3 \%$ for both ZB and W phases, respectively. ii) RS phase presents a bulk modulus approximately $25 \%$ larger than the value for $\mathrm{ZB}$ and $\mathrm{W}$ structures. This decrease of the bulk compressibility is caused by the rearrangement of the polyhedral units that takes place at the transition. W presents highly anisotropic behaviour under compression with larger compressibility of the $c$-axis compared to a-axis. iii) The DOS analysis of ZnS polymorphs evidences changes in the VB and $\mathrm{CB}$ with a linear increase of the band gap value with the pressure, having a major impact on $\mathrm{CB}$. iv) $\mathrm{ZB}$ and $\mathrm{W}$ phases a higher variation in the band gap energies with increasing pressure 
than for RS phase, according to other theoretical and experimental studies. v) The calculated binding energies for the $\mathrm{Zn} 3 d$ band is consistent with experimental XPS data. v) from the analysis of the atomic contributions of $\mathrm{CB}$ and $\mathrm{VB}$, we obtain that the chemical bond between sulfur and the zinc atom in the $\mathrm{ZnS}$ polymorphs is predominantly covalent for $\mathrm{W}$ and $\mathrm{ZB}$ phases and more ionic for $\mathrm{RS}$ one. vi) The characterization of Raman-active vibrational frequencies for $\mathrm{W}$ and $\mathrm{ZB}$ structures and the Grüneisen parameters show a soft mode with symmetry $E_{2}$ for $\mathrm{W}$ phase, associated to an asymmetric bending between $\mathrm{Zn}-\mathrm{S}$ units, suggesting that at higher pressure the hexagonal phase should undergo reconstructive phase transition with a strong coupling between a zone-centre optic mode and a strain, in this case of $E_{2}$ symmetry.

\section{ACKNOWLEDGMENTS}

The authors gratefully acknowledge the financial support of the Brazilian agencies CAPES, CNPq and FAPESP. J.A. also acknowledges Generalitat Valenciana for Prometeo/2009/053 project, Ministerio de

Ciencia e Innovación for project CTQ-2012-36253-C03-01CTO, and Programa de Cooperación Científica con Iberoamerica (Brasil), Ministerio de Educación (PHB2009-0065-PC).

\section{REFERENCES}

1. Odom, T.W.; Henzie, J.; Babayan, Y.; Greyson, E.C.; Kwak, E.S. Optical Properties of SurfacePatterned Nanostructures. Talanta 2005, 67, 507-513.

2. Early, K. T.; Nesbitt, D. J. Size-Dependent Photoionization in Single CdSe/ZnS Nanocrystals. Nano Lett. 2013, 13 (10), 4844-4849.

3. Raubach, C. W.; De Santana, Y. V. B.; Ferrer, M. M.; Buzolin, P. G. C.; Sambrano, J. R.; Longo, E. Photocatalytic activity of semiconductor sulfide heterostructures. Dalton Trans. 2013, 42, 11111-11116. 
4. Yang, J.; Wang, B.; Cao, J.; Han, D.; Feng, B.; Wei, M.; Fan, L.; Kou, C.; Liu, Q.; Wang, T. Controllable photoluminescent-magnetic dual-encoded wurtzite $\mathrm{ZnS}: \mathrm{Cu}^{2+} \mathrm{Mn}^{2+}$ nanowires modulated by $\mathrm{Cu}^{2+}$ and $\mathrm{Mn}^{2+}$ ions. J. Alloys Compd. 2013, 574, 240-245.

5. Fang, X.; Zhai, T.; Gautam, U.K.; Li, L.; Wu, L.; Bando, Y.; Golberg, D. ZnS nanoparticles: From synthes is to applications. Prog. Mater. Sci. 2011, 56, 175-287.

6. La Porta, F. A.; Ferrer, M. M.; Santana, Y. V. B.; Raubach, C. W.; Longo, V. M.; Sambrano, J. R.; Longo, E.; Andrés, J.; Li, M. S.; Varela, J. A. Synthesis of wurtzite ZnS nanoparticles using the microwave assisted solvothermal method. J. Alloys Compd. 2013, 555, 153-159.

7. Wagner, H. P.; Kühnelt, M.; Langbein, W.; Hvam, J. M. Dispersion of the second-order nonlinear susceptibility in ZnTe, ZnSe, and ZnS. Phys. Rev. B1998, 58, 10494-10501.

8. Brafman, O.; Mitra, S. S. Phys. Rev. 1968, 171, 931-934.

9. Ding, Y.; Wang, X. D.; Wang, Z. L. Phase controlled synthesis of ZnS nanobelts: zinc blende vs wurtzite. Chem. Phys. Lett. 2004, 398, 32-36.

10. Prior, K. A.; Bradford, C.; Davidson, I. A.; Moug, R. T. Metastable II-VI sulphides: Growth, characterization and stability. J. Cryst. Growth 2011, 323, 114-121.

11. Uchino, M.; Mashimo, T.; Kodama, M.; Kobayashi, T.; Takasawa, E.; Sekine, T.; Noguchi, Y.; Hikosaka, H.; Fukuoka, K.; Syono, Y.; Kondo, T.; Yagin, T. Phase transition and EOS of zinc sulfide under shock and static compressions up to 135 GPa. J. Phys. Chem. Solids 1999, 60, 827837.

12. Hou, L.; Gao, F. Phase and morphology controlled synthesis of high-quality ZnS nanocrystals. Mater. Lett. 2011, 65, 500-503.

13. Huang, F.; Banfield, J. F. Size-Dependent Phase Transformation Kinetics in Nanocrystalline ZnS. J. Am. Chem. Soc. 2005, 127 (12), 4523-4529. 
14. Tong, H.; Zhu, Y. J.; Yang, L. X.; Li, L.; Zhang, L.; Chang, J.; An, L. Q.; Wang, S. W. SelfAssembled ZnS Nanostructured Spheres: Controllable Crystal Phase and Morphology. J. Phys. Chem. C 2007, 111, 3893-3900.

15. Feigl, C. A.; Barnard, A. S.; Russo, S. P. Size- and shape-dependent phase transformations in wurtzite ZnS nanostructures. Phys. Chem. Chem. Phys. 2012, 14, 9871-9879.

16. Onwudiwe, D. C.; Krüger, T. P.; Strydom, C. A. Laser assisted solid state reaction for the synthesis of $\mathrm{ZnS}$ and $\mathrm{CdS}$ nanoparticles from metal xanthate, Mater. Lett. 2013, in press.

17. Wang, Z. W.; Daemen, L. L.; Zhao, Y. S.; Zha, C. S.; Downs, R. T.; Wang, X. D.; Wang, Z. L.; Hemley, R. J. Morphology-tuned wurtzite-type ZnS nanobelts. Nat. Mater. 2005, 4, 922-927.

18. Siqueira, G. O.; Matencio, T.; da Silva, H. V.; de Souza, Y. G.; Ardisson, J. D.; de Lima, G. M.; Porto, A. O. Temperature and time dependence on $\mathrm{ZnS}$ microstructure and phases obtained through hydrothermal decomposition of diethyldithiocarbamate complexes. Phys.Chem. Chem. Phys. 2013, 15, 6796-6803.

19. Hosokawa, H.; Murakoshi, K.; Wada, Y.; Yanagida, S.; Satoh, M. Extended X-ray Absorption Fine Structure Analysis of ZnS Nanocrystallites in N,N-Dimethylformamide. An Effect of Counteranions on the Microscopic Structure of a Solvated Surface. Langmuir 1996, 12, 35983603.

20. Huang, F.; Zhang, H.; Banfield, J. F. Two-Stage Crystal-Growth Kinetics Observed during Hydrothermal Coarsening of Nanocrystalline ZnS. Nano Lett. 2003, 3 (3), 373-378.

21. Cheng, Y. C.; Jin, C. Q.; Gao, F.; Wu, X. L.; Zhong, W.; Li, S. H.; Chu, P. K. Raman scattering study of zinc blende and wurtzite ZnS. J. Appl. Phys. 2009, 106, 123505.

22. Santana, Y. V. B.; Raubach, C. W.; Ferrer, M. M.; La Porta, F.; Sambrano, J. R.; Longo, V. M.; Leite, E. R.; Longo, L. Experimental and theoretical studies on the enhanced photoluminescence activity of zinc sulfide with a capping agent. J. Appl. Phys. 2011, 110, 123507. 
23. Pan, Q.; Yang, D.; Zhao, Y.; Ma, Z.; Dong, G.; Qui, J. Facile hydrothermal synthesis of Mn doped ZnS nanocrystals and luminescence properties investigations. J. Alloys Compd. 2013, 579, 300-304.

24. Hohenberg, P.; Kohn, W. Inhomogeneous Electron Gas. Phys. Rev. 1964, 136, B864-B871

25. Kohn, W.; Sham, L. J. Self-Consistent Equations Including Exchange and Correlation Effects. Phys. Rev. 1965, 140, A1133-A1138.

26. Zhao, Y.; Truhlar, D. G. Density Functionals with Broad Applicability in Chemistry. Acc. Chem. Res. 2008, 41 (2), 157-167.

27. Neugebauer, J.; Hickel, T. Density functional theory in materials science. WIREs Compt. Mol. Sci. 2013, 3, 1-11.

28. Krainara, N.; Limtrakul, J.; Illas, F.; Bromley, S. T. Magic Numbers in a One-Dimensional Nanosystem: ZnS Single-Walled Nanotubes. J. Phys. Chem. C 2013, 117 (44), 22908-22914.

29. Longo, V. M.; Gracia, L.; Stroppa, D. G.; Cavalcante, L. S.; Orlandi, M.; Ramirez, A. J.; Leite, E. L.; Andrés, J.; Beltrán, A.; Varela, J. A.; Longo, E. A Joint Experimental and Theoretical Study on the Nanomorphology of CaWO 4 Crystals. J. Phys. Chem. C 2011, 115 (41), 20113-20119.

30. Koch,W.; Holthausen, M. C. A Chemist's Guide to Density Functional Theory; Wiley-VCH: New York, 2001.

31. Paier, J.; Marsman, M.; Kresse, G. Why does the B3LYP Hybrid Functional Fail for Metals? J. Chem. Phys. 2007, 127 (2), 024103-124112.

32. Albuquerque, A. R.; Maul, J.; Longo, E.; dos Santos, I. M. G.; Sambrano, J. R. Hydrostatic and [001] Uniaxial Pressure on Anatase $\mathrm{TiO}_{2}$ by Periodic B3LYP-D* Calculations. J. Phys. Chem. C 2013, 117 (14), 7050-7061.

33. Albuquerque, A. R.; Garzim, M. L.; dos Santos, I. M. G.; Longo, V.; Longo, E.; Sambrano, J. R. DFT Study with Inclusion of the Grimme Potential on Anatase $\mathrm{TiO}_{2}$ : Structure, Electronic, and Vibrational Analyses. J. Phys. Chem. A 2012, 116 (47), 11731-11735. 
34. La Porta, F. A.; Giacoppo, J. O. S.; Ramos, P. H.; Guerreiro, M. C.; Ramalho, T. C. Computational Insights into the Role of the Frontiers Orbital in the Chemistry of Tridentate Ligands. American Journal of Chemistry 2012, 2 (5), 255-262.

35. Grimme, S. Accurate description of van der Waals complexes by density functional theory including empirical corrections. J. Comput. Chem. 2004, 25, 1463-1473.

36. Grimme, S. Semiempirical GGA-type density functional constructed with a long-range dispersion correction. J. Comput. Chem. 2006, 27, 1787-1799.

37. Grimme, S.; Antony, J.; Ehrlich, S.; Krieg, H. A consistent and accurate ab initio parametrization of density functional dispersion correction (DFT-D) for the 94 elements $\mathrm{H}-\mathrm{Pu}$. J. Chem. Phys. 2010, 132 (19), 154104.

38. Dovesi, R.; Saunders, V. R.; Roetti, C.; Orlando, R.; Zicovich-Wilson, C. M.; Pascale, F.; Civalleri, B.; Doll, K.; Harrison, N. M.; Bush, I. J.; Arco, P. D.; Llunell, M. CRYSTAL09 Users Manual, University of Torino, 2009.

39. Durandurdu, M. Pressure-induced phase transition in wurtzite $\mathrm{ZnS}$ : An ab initio constant pressure study. J. Phys. Chem. Solids 2009, 70, 645-649.

40. Franco, R.; Mori-Sánchez, P.; Recio, J. M.; Pandey, R. Theoretical compressibilities of highpressure ZnTe polymorphs. Phys. Rev. B2003, 68, 195208.

41. Jaffe, J. E.; Pandey, R.; Seel, M. J. Ab initio high-pressure structural and electronic properties of ZnS. Phys. Rev. B1993, 47, 6299.

42. Gracia, L.; Beltrán, A.; Andrés, J. Characterization of the High-Pressure Structures and Phase Transformations in $\mathrm{SnO}_{2}$. A Density Functional Theory Study. J. Phys. Chem. B 2007, 111, 64796485.

43. Gracia, L.; Beltrán, A.; Andrés, J. A Theoretical Study on the Pressure-Induced Phase Transitions in the Inverse Spinel Structure $\mathrm{Zn}_{2} \mathrm{SnO}_{4}$. J. Phys. Chem. C 2011, 115, 7740-7746.

44. Becke, A. D. Density-functional thermochemistry. III. The role of exact exchange. J. Chem. Phys. 1993, $98,5648-5653$. 
45. Lee, C.; Yang, W.; Parr, R. G. Development of the Colle-Salvetti correlation energy formula into a functional of the electron density. Phys. Rev. B. 1988, 37, 785-789.

46. Pisani, C.; Dovesi, R.; Roetti, C. Hartree-Fock Ab Initio Treatment of Crystalline Systems. Springer-Verlag, Berlin, 1988.

47. Powell, M. J. D. A survey of numerical methods for unconstrained optimization. SIAM Rev. $1970,12,79$.

48. Monkhorst, H. J.; Pack, J. D. Special points for Brillouin-zone integrations. Phys. Rev. 1976, 13, 5188.

49. http://www.crystalimpact.com/diamond/download.htm.

50. Blanco, M. A.; Francisco, E.; Luana, V. GIBBS: isothermal-isobaric thermodynamics of solids from energy curves using a quasi-harmonic Debye model. Compu. Phys. Comm. 2004, 158, 5772.

51. Kokalj, A. XCrySDen - a new program for displaying crystalline structures and electron densities. J. Mol. Graphics. Modell. 1999, 17, 176-179.

52. Kisi, E. H.; Elcombe, M. M. u parameters for the wurtzite structure of $\mathrm{ZnS}$ and $\mathrm{ZnO}$ using power neutron diffraction. Acta Cryst. 1989, C45, 1867-1870

53. Reddy, D. A.; Divya, A.; Murali, G.; Vijayalakshmi, R. P.; Reddy, B. K. Synthesis and optical properties of $\mathrm{Cr}$ doped $\mathrm{Zn} \mathrm{S}$ nanoparticles capped by 2-mercaptoethanol. Phys. B 2011, 406, 1944-1949.

54. Nazzal, A.; Qteish, A. Ab initio pseudopotential study of the structural phase transformations of ZnS under high pressure. Phys. Rev. B.1996, 53,8262-8266.

55. Catti, M.; Noel, Y.; Dovesi, R. Full piezoeletric tensors of wurtzite and zinc blende $\mathrm{ZnO}$ and $\mathrm{ZnS}$ by first-principles calculations. J. Phys. Chem. Solids 2003, 64, 2183-2190. 
56. Wang, Y. R.; Duke, C. B. Atomic and electronic structure of ZnS cleavage surfaces. Phys. Rev. B 1987, $36(5), 2763-2769$.

57. Mujica, A.; Rubio, A.; Muñoz, A.; Needs, R. J. High-pressure phases of group-IV, III-V, and IIVI compounds. Rev. Mod. Phys. 2003, 75, 863-912.

58. Mulinari, T. A.; La Porta, F. A.; Andrés, J.; Cilense, M.; Varela, J. A.; Longo, E. Microwavehydrothermal synthes is of single-crystalline $\mathrm{Co}_{3} \mathrm{O}_{4}$ spinel nanocubes. CrystEngComm 2013, 15, 7443-7449.

59. Nilsen, W. G. Raman spectrum of cubic ZnS. Phys. Rev. 1969, 182, 838-850.

60. Bomio, M. R. D.; Tranquilin, R. L.; Motta, F. V.; Paskocimas, C. A.; Nascimento, R. M.; Gracia, L.; Andres, J.; Longo, E. Toward Understanding the Photocatalytic Activity of $\mathrm{PbMoO}_{4} \mathrm{Powders}$ with Predominant (111), (100), (011), and (110) Facets. A Combined Experimental and Theoretical Study. J. Phys. Chem. C 2013, 117, 21382-21395.

61. Azpiroz, J. M.; Infante, I.; Lopez, X.; Ugalde, J. M.; De Angelis, F. A first-principles study of IIVI (II = Zn; VI = O, S, Se, Te) semiconductor nanostructures. J. Mater. Chem. 2012, 22, 2145321465.

62. La Porta, F. A.; Ramalho, T. C.; Santiago, R. T.; Rocha, M. V J.; Cunha, E. F. F. Orbital Signatures as a Descriptor of Regioselectivity and Chemical Reactivity: The Role of the Frontier Orbitals on 1,3-Dipolar Cycloadditions J. Phys. Chem. A 2011, 115, 824-833.

63. La Porta, F. A.; Santiago, R. T.; Ramalho, T. C.; Freitas, M. P.; Cunha, E. F. F. The role of the Frontier orbitals in acid-base chemistry of organic amines probed by ab initio and chemometric techniques. Int. J. Quantum Chem. 2010, 110, 2015-2023.

64. Desgreniers, S.; Beaulieu, L.; Lepage, I. Pressure-induced structural changes in ZnS. Phys. Rev. B 2000, 61, 8726-8733.

65. Zhou, Y.; Campell, A. J.; Heinz, D. L. Equations of state and optical properties of the high pressure phase of zinc sulfide. J. Phys. Chem. Solids 1991, 52, 821-825. 
66. Pan, Y.; Qu, S.; Dong, S.; Cui, Q.; Zhang, W.; Liu, X.; Liu, J.; Liu, B.; Gao, C.; Zou, G. An investigation on the pressure-induced phase transition of nanocrystalline $\mathrm{ZnS}$. J. Phys.: Condens. Matter. 2002, 14, 10487.

67. Ves, S.; Schwarz, U.; Christensen, N. E.; Syassen, K.; Cardona, M. Cubic ZnS under pressure: Optical-absorption edge, phase transition, and calculated equation of state. Phys. Rev. B1990, 42, 9113-9118.

68. Yue-wu, P.; Shengchun, Q.; Gao, C.; Yonghao, H.; Jifeng, L.; Qiliang, C.; Jing, L.; Guangtian, Z. Structural Phase Transformations of ZnS Nanocrystalline Under High Pressure. Chin. Phys. Lett. 2004, 21, 67.

69. Catti, M. First-principles study of the orthorhombic mechanism for the B3/B1 high-pressure phase transition of ZnS, Phys. Rev. B2002, 65, 224115.

70. Kirin, D.; Lukačević, I. Stability of high-pressure phases in II-VI semiconductors by a density functional lattice dynamics approach, Phys. Rev. B2007, 75, 172103.

71. Basak, T.; Rao, M. N.; Gupta, M. K.; Chaplot, S. L. Vibrational properties and phase transitions in II-VI materials: lattice dynamics, ab initio studies and inelastic neutron scattering measurements, J. Phys.: Condens. Matter 2012, 24, 115401.

72. Reparaz, J. S.; Muniz, L. R.; Wagner, M. R.; Goñi, A. R.; Alonso, M. I.; Hoffmann, A.; Meyer, B. K. Reduction of the transverse effective charge of optical phonons in $\mathrm{ZnO}$ under pre ssure. Appl. Phys Lett. 2010, 96, 23906.

73. Gupta, S. K.; Kumar, S.; Auluck, S. Electronic and optical properties of high pressure stable phase of ZnS: Comparison of FPLAPW and PW-PP results. Opt. Commun. 2011, 284, 20-26.

74. Huang, Y.-H; Jie, W.-Q; Zhou, Y.; Zha, G.-Q. Structural stability, band structure and magnetic properties of $\mathrm{ZnS}$ and $\mathrm{Zn}_{0.75} \mathrm{Cr}_{0.25} \mathrm{~S}$ under pressure. J. Alloys Compd. 2013, 549, 184-189. 